\title{
The Insula Mediates Access to Awareness of Visual Stimuli Presented Synchronously to the Heartbeat
}

\author{
Roy Salomon, ${ }^{1,2}$ Roberta Ronchi, ${ }^{1,2}$ Jonathan Dönz, ${ }^{1,2}$ Javier Bello-Ruiz, ${ }^{1,2}$ Bruno Herbelin, ${ }^{1,2}$ Remi Martet, ${ }^{1,2}$ \\ Nathan Faivre, ${ }^{1,2}$ Karl Schaller, ${ }^{4}$ and Olaf Blanke ${ }^{1,2,3}$ \\ ${ }^{1}$ Laboratory of Cognitive Neuroscience and ${ }^{2}$ Center for Neuroprosthetics, School of Life Sciences, Ecole Polytechnique Fédérale de Lausanne, Geneva 1202 , \\ Switzerland; ${ }^{3}$ Department of Neurology and ${ }^{4}$ Neurosurgery Division, Department of Clinical Neurosciences, Geneva University Hospitals, Geneva 1211, \\ Switzerland
}

The processing of interoceptive signals in the insular cortex is thought to underlie self-awareness. However, the influence of interoception on visual awareness and the role of the insular cortex in this process remain unclear. Here, we show in a series of experiments that the relative timing of visual stimuli with respect to the heartbeat modulates visual awareness. We used two masking techniques and show that conscious access for visual stimuli synchronous to participants' heartbeat is suppressed compared with the same stimuli presented asynchronously to their heartbeat. Two independent brain imaging experiments using high-resolution fMRI revealed that the insular cortex was sensitive to both visible and invisible cardio-visual stimulation, showing reduced activation for visual stimuli presented synchronously to the heartbeat. Our results show that interoceptive insular processing affects visual awareness, demonstrating the role of the insula in integrating interoceptive and exteroceptive signals and in the processing of conscious signals beyond self-awareness.

Key words: continuous flash suppression; high-resolution fMRI; insula; interoception; visual awareness

Significance Statement

There is growing evidence that interoceptive signals conveying information regarding the internal state of the body influence perception and self-awareness. The insular cortex, which receives sensory inputs from both interoceptive and exteroceptive sources, is thought to integrate these multimodal signals. This study shows that cardiac interoceptive signals modulate awareness for visual stimuli such that visual stimuli occurring at the cardiac frequency take longer to access visual awareness and are more difficult to discriminate. Two fMRI experiments show that the insular region is sensitive to this cardio-visual synchrony even when the visual stimuli are rendered invisible through interocular masking. The results indicate a perceptual and neural suppression for visual events coinciding with cardiac interoceptive signals.

\section{Introduction}

Human awareness remains one of the most profound mysteries for science (Searle et al., 1997). Significant advances have been made regarding the mechanisms of awareness, notably through

Received Nov. 26, 2015; revised March 23, 2016; accepted March 29, 2016.

Author contributions: R.S., J.D., N.F., K.S., and 0.B. designed research; R.S., R.R., J.D., and R.M. performed research; J.B.-R. and B.H. contributed unpublished reagents/analytic tools; R.S., R.R., J.D., J.B.-R., B.H., N.F., and O.B. analyzed data; R.S., R.R., J.D., N.F., K.S., and O.B. wrote the paper

$0 . B$. is supported by the Bertarelli Foundation, the Swiss National Science Foundation, and the European Science Foundation. R.S was supported by the National Center of Competence in Research, $n(C R)$ "SYNAPSY - The Synaptic Bases of Mental Diseases" financed by the Swiss National Science Foundation (no. 51AU40_125759). N.F. is an École Polytechnique Fédérale de Lausanne Fellow cofunded by a Marie Skłodowska-Curie fellowship and was also supported by the European Union Human Brain Project. We thank Rafael Malach, Aaron Schuger, and Andrea Serino for valuable comments on the study.

The authors declare no competing financial interests.

Correspondence should be addressed to Roy Salomon, Laboratory of Cognitive Neuroscience, École Polytechnique Fédérale de Lausanne (EPFL), Chemin des Mines 9, Genève 1202, Switzerland. E-mail: royesal@gmail.com.

DOI:10.1523/JNEUROSCI.4262-15.2016

Copyright $\odot 2016$ the authors $\quad 0270-6474 / 16 / 365115-13 \$ 15.00 / 0$ psychophysical and neural measures of conscious and unconscious processing of visual stimuli (Dehaene and Changeux, 2011). Another line of work has linked self-awareness to the processing of interoceptive signals in the insular cortex (i.e., cardiac signals; Damasio, 2000; Craig, 2002; Critchley et al., 2004; Park et al., 2014) that monitor the internal state of the body (Craig, 2009b; Singer et al., 2009; Craig, 2010). Recently, theories have suggested that the insula may be involved in interoceptive inference in which predictions regarding interoceptive signals are compared with actual sensory and interoceptive afferent inputs (Critchley and Seth, 2012; Seth, 2013; Apps and Tsakiris, 2014). These predictive models of interoception are held to mediate widespread sensory consequences of interoceptive signals such as cardiac activity (Barrett and Simmons, 2015), thus reducing their influence on perception (comparable to suppression of retinal changes due to ocular motion). Early work on cardiac effects on cortical processing has shown a general suppression of cortical excitability related to cardiac activity (Lacey and Lacey, 1970; 
Koriath and Lindholm, 1986). Others have found evidence for cardiac related modulation of sensory and cortical processing for cutaneous (Edwards et al., 2009; Gray et al., 2009), nociceptive (Edwards et al., 2001; Gray et al., 2010), and emotional stimuli (Garfinkel et al., 2014). However, studies investigating cardiac modulation of visual perception have produced conflicting results (Elliott and Graf, 1972; Sandman et al., 1977; Walker and Sandman, 1982; Park et al., 2014). Therefore, although interoceptive signals seem important for self and bodily awareness (Craig, 2009b; Aspell et al., 2013; Suzuki et al., 2013), their role in other forms of awareness such as visual awareness is yet unclear. Here, we report data from a series of behavioral and brain imaging studies investigating the modulation of visual awareness by interoceptive bodily signals in classical psychophysical tasks. We explored the impact of interoceptive signals on visual awareness in a series of nine separate experiments using novel adaptations of the continuous flash suppression (CFS) (Tsuchiya and Koch, 2005) and visual crowding (Bouma, 1970) paradigms. These data reveal an impact of interoceptive signals on visual awareness, in which visual targets presented synchronously to the cardiac frequency require more time (CFS) and are more difficult to discriminate (visual crowding) than the same stimuli presented asynchronously to the heartbeat. Two high-resolution fMRI experiments show that the cardio-visual effect is reflected by insular cortex activity, thus demonstrating that the processing of internal bodily signals in the insular cortex modulates exteroceptive awareness.

\section{Materials and Methods Participants}

We recruited 153 right-handed healthy volunteers (46 females) from the student population at École Polytechnique Fédérale de Lausanne (EPFL) (age 18-32 years, $\mu=22.2$ years) for the first 7 experiments (Experiment 1, $n=31$; Experiment 2, $n=18$; Experiment 3, $n=23$, i.e., participants in Experiment 1 who agreed to return; Experiment 4, $n=33$; Experiment 5, $n=17$; Experiment 6, $n=15$; Experiment 7, $n=16$ ). Ten participants were excluded from the analysis (Experiment $1, n=1$; Experiment 2, $n=$ 3; Experiment 4, $n=3$; Experiment 5, $n=2$; Experiment 7, $n=1$ ). Of these 10 participants, 6 were removed due to technical failures [electrode detachment during the experiment (4 of 6 participants); cluttered presentation of the target stimuli due to malfunction in one of the headmounted display (HMD) lenses ( 2 of 6 participants)]; the remaining four subjects were excluded due to accuracy scores 2.5 SDs below the mean $(63 \%, 49 \%, 58 \%)$ and another one due to chance accuracy scores in the crowding experiment (37\%). Therefore, the final data for analysis in the psychophysical experiments consisted of 143 participants. All participants had normal or corrected-to-normal vision, were right-handed, had no psychiatric or neurological history, and were naive with respect to the purpose of the study. They participated in the study for payment $(\sim 30$ Swiss Francs, CHF). All participants gave informed consent and the study was approved by the ethics committee of EPFL.

\section{Stimuli and procedure}

\section{Experiment 1: CFS experiment}

Stimuli. Stimuli consisted of high-contrast color dynamic noise patches suppressors ("Mondrians") and target stimuli. The target image consisted of a yellow octagon (RGB: $255,255,0$; visual angle: $\mathrm{H}: 4^{\circ}, \mathrm{V}: 4^{\circ}$ ) positioned either above or below a central fixation cross (RGB: 0,0,0; visual angle: $\left.\mathrm{H}: 1^{\circ}, \mathrm{V}: 1^{\circ}\right)$. Mondrians were rapidly $(10 \mathrm{~Hz})$ flashed to the participants' dominant eye (visual angle: $\mathrm{H}: 48^{\circ}, \mathrm{V}: 36^{\circ}$ ) and the target was presented simultaneously to the other eye. A black fixation cross (RGB: $0,0,0$; visual angle: $\mathrm{H}: 1^{\circ}, \mathrm{V}: 1^{\circ}$ ) was presented to both eyes in all conditions. Stimuli were presented using ExpyVR custom-built multimedia stimuli presentation software developed with Python version 2.6 and the Open Graphics Library version 2.2. The stimuli were viewed via an HMD
(VR1280; Immersion, SXGA, $60^{\circ}$ diagonal field of view, refresh rate 60 $\mathrm{Hz})$.

Heartbeat detection and online graphical animation. For the acquisition of the ECG signal, electrodes were placed on the subjects' chest and plugged into a biometric analog signal amplifier (e-Health Sensor Platform version 2.0; Libelium) that was assembled together with a microcontroller (ATmega328; Arduino UNO) that performed the heartbeat detection.

Procedure. The CFS experiment included 160 trials divided into four blocks. The total duration of the experiment was $\sim 1 \mathrm{~h}$. Each trial began with the simultaneous presentation of the dynamic high-contrast color patterns ("masks") and a target image to separate eyes (Fig. 1a). The trial ended when participants pressed a key to indicate their response or after a maximum of $20 \mathrm{~s}$. Target location (above/below fixation) and cardiovisual synchrony (synchronous/asynchronous) were randomized. Two different cardio-visual asynchronies were used, either $80 \%$ or $120 \%$ of the participant's current heartbeat, and were counterbalanced between subjects. To ensure that trial onset did not maintain a specific phase in relation to participants' heartbeat, an intertrial interval of $0.5,0.8$, or $1.3 \mathrm{~s}$ was presented between trials such that any spurious temporal relation between cardiac and visual stimuli would not be maintained.

\section{Experiment 2: CFS replication within subjects}

To verify and replicate the results found in Experiment 1, we ran a second experiment on 15 subjects in which both versions of the asynchronous cardio-visual stimulation were used in a within-subject design. The experimental design was identical to that of the first experiment except, here, each participant had 80 synchronous and 80 asynchronous trials of cardio-visual stimulation (for asynchronous stimulation 40 trials were at $120 \%$ of the participant's heartbeat and the other 40 were at $80 \%$ of their heartbeat).

\section{Experiment 3: heartbeat awareness}

In this experiment, we tested the ability of participants to judge whether the flashing stimuli were synchronous or asynchronous with their heartbeat (heartbeat awareness). Twenty-three participants from the cohort of the Experiment 1 were tested. Here, we presented the same visual stimuli as in Experiments 1 and 2 (an octagon flashing either synchronously or asynchronously to each participant's heartbeat), but with no interocular suppression, for a duration of $6 \mathrm{~s}$. Participants were required to report whether the flashing stimulus was synchronous or asynchronous to their current heartbeat by pressing a button on the keyboard. The participants were explicitly asked not to monitor their heartbeat by means other than interoceptive attention (such as taking their pulse). There were 100 trials in total (50 synchronous and 50 asynchronous randomized). The duration of the experiment was $\sim 20 \mathrm{~min}$.

\section{Experiment 4: CFS control}

We used a classical CFS control experiment (Jiang et al., 2007; Salomon et al., 2013) to control for possible differences in detection time due to response or detection biases. The control experiment was identical to Experiment 1 except that the target image (the yellow octagon) was blended into the masks (Fig. 1c) and presented to both eyes. Therefore, in the control experiment, there was no interocular suppression. Comparison of the results from the control and CFS experiments allowed us to test whether the results in the CFS experiment reflected a mere response bias rather than a difference in conscious access.

\section{Experiment 5: visual control}

We used a visual control experiment to ensure that our results in Experiments 1 and 2 were not due to any visual characteristics relating to frequency effects of the stimulus presentation, but rather were due to subject specific cardio-visual coupling. This experiment was identical to Experiment 2 except that each participant in Experiment 5 was shown the precise visual stimulation shown previously to a participant in Experiment 2 (replayed) but without any relation to the participant's own current heartbeat. The visual stimulation was thus identical in both experiments but the cardio-visual coupling was absent in Experiment 5. Therefore, if the visual features of the stimuli (such as frequency or timing differences) were driving the difference between synchronous and 
a Experimental set-up

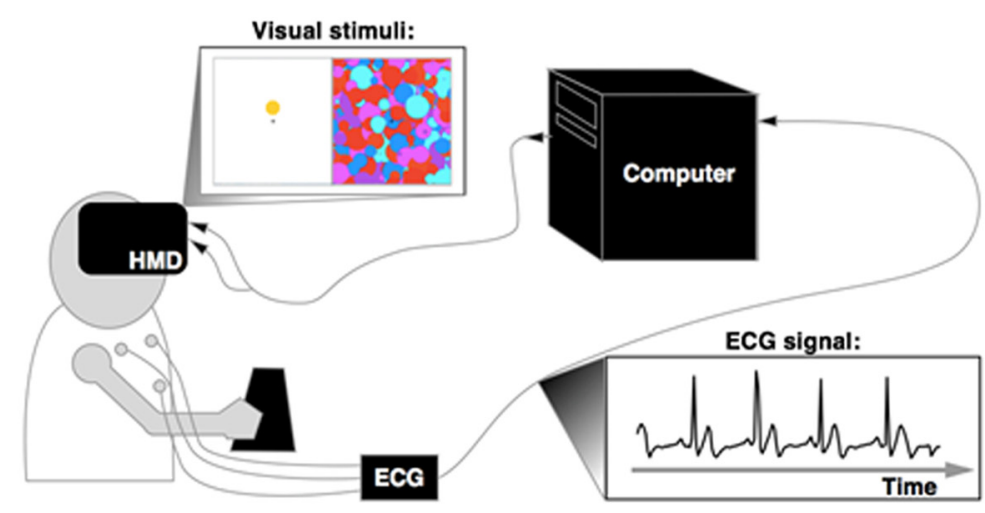

C b

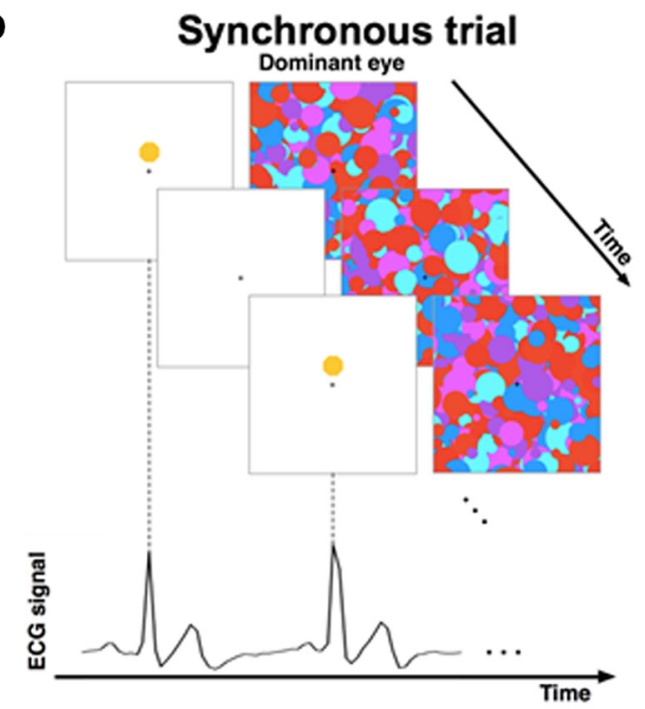

Asynchronous trial

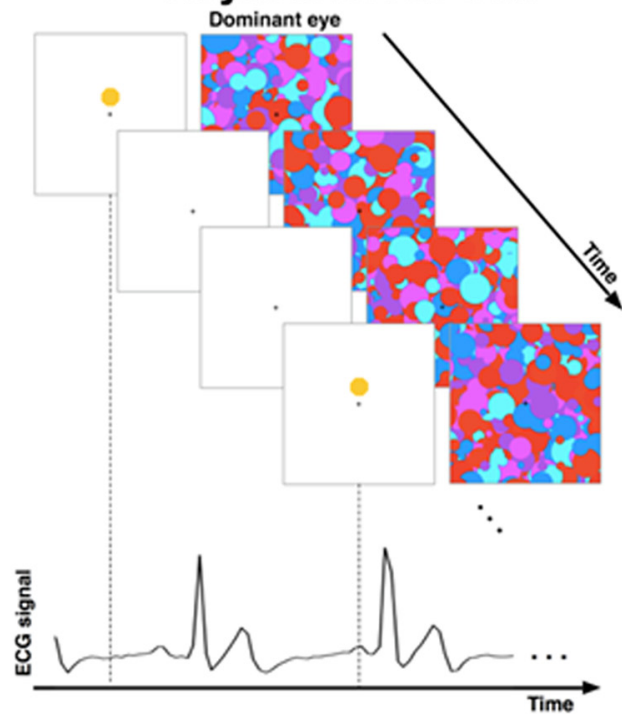

Figure 1. Experimental setup and paradigm. $\boldsymbol{a}$, The participant wore an HMD while her heart rate was recorded by ECG. The ECG signal was recorded in real time and was sent to a computer that generated visual stimuli flashing at the frequency of the participant's heartbeat (synchronous trials) or at a modified frequency (asynchronous trials). $\boldsymbol{b}$, Sequence of visual stimuli presented to the participant in the synchronous (top) and asynchronous condition (bottom). The Mondrian patterns were presented to the dominant eye at a fixed frequency of $10 \mathrm{~Hz}$ and the target (yellow octagon) was flashed to the other eye. In synchronous trials, the flashes of the target corresponded to the moment of the QRS complex obtained from the ECG signal and reflecting systolic contraction. The task of the participants was to indicate the position of the target with respect to the fixation cross (above or below). c, CFS control experiment (Experiment 4) in which Mondrian patterns and the target stimuli were presented to both eyes without any binocular rivalry to control for detection and response biases.

asynchronous stimuli, then we would expect the participants to show similar differences between the trials that were synchronous and asynchronous in Experiment 2.

\section{Experiment 6: phase-shifted CFS}

We next investigated whether the frequency of presentation of a visual stimulus congruent to the heart rate was sufficient to cause visual suppression or if it also had to be presented at a precise moment relative to the heartbeat cycle. Therefore, we used the same CFS paradigm as in the previous experiments with the target flashing at the frequency of the participant's heart rate in both conditions. However, in this experiment, we modulated the phase (delay) of the visual stimulation relative to an event of the heartbeat's cycle. In the synchronous condition, the target was presented at the R peak of the QRS complex, as in the synchronous conditions of all previous experiments. In the present phase-shifted condition, target presentation was delayed by a half of the heartbeat period with respect to the $\mathrm{R}$ peak. Based on previous studies indicating large temporal variability for heartbeat detection and heartbeat-evoked electrophysiological responses (Brener and Kluvitse, 1988; Leopold and
Schandry, 2001; Knapp-Kline and Kline, 2005; van Elk et al., 2014a), we predicted that the frequency synchrony rather than precise phase is the target of cardio-visual suppression. If the visual suppression is related only to the heartbeat's frequency information, that is, with no consideration of the phase of the stimulus relative to the heartbeat's cycle, then we expected to see no difference in the duration of target presentation required to break suppression in the two present conditions. However, if visual suppression is related to the exact moment of the QRS, then the present phase-shifted condition should show less suppression.

\section{Experiment 7: visual crowding}

To further address this issue of phase versus frequency modulation and to test the robustness of the frequency synchronous suppression of visual awareness, we used a novel experimental psychophysical design relying on visual crowding (Whitney and Levi, 2011). This is a drastically different paradigm from the previously used cardio-visual CFS paradigm because it does not depend on interocular competition and does not rely on reaction times as a dependent measure. Rather, visual crowding involves limits of peripheral resolution in binocular vision and is reflected by a 
decrease of accuracy in nonspeeded discrimination tasks (for reviews see Levi, 2008; Whitney and Levi, 2011).

Stimuli and procedure. The crowding experiment included 288 trials divided into 6 blocks and lasted $\sim 1 \mathrm{~h}$. Each trial began with the simultaneous presentation of $\mathrm{H}: 1^{\circ}$ by $\mathrm{V}: 1^{\circ}$ fixation cross at the top of the screen and an array of peripheral stimuli $8.7^{\circ}$ below. This array comprised an $0.45^{\circ}$ by $0.6^{\circ}$ target (letter symbols: “ $\lrcorner$ ", “ $\perp$ ”, or “ $L$ ”) surrounded by eight flankers of the same size (letter symbol: "I"; center-to-center distance between target and flankers: $0.72^{\circ}, 0.91^{\circ}, 1.1^{\circ}$, or $1.29^{\circ}$; see Fig. $3 a$ ). All stimuli were displayed in black against a white background (Michelson contrast $=1$ ). Although the flankers were displayed with a constant contrast, the target was flashed according to the participant's heartbeat (synchronous, $80-120 \%$ asynchronous, and delayed by $300 \mathrm{~ms}$ ). The 500 ms flashing animation was done by applying a positive section of a sine function to the transparency of the target shape. Participants were asked to discriminate the target's letter symbol as quickly and accurately as possible (i.e., three alternative forced-choice task) while constantly fixating the fixation cross. Stimuli were presented for $6 \mathrm{~s}$, during which participants could provide an answer with a key press at any time. If no response was provided at the end of this period, the 3 target letter symbols were presented for another $2 \mathrm{~s}$, during which the subject provided a response. The target type, center-to-center distance between target and flanker, and cardio-visual synchronicity were fully randomized. A $1 \mathrm{~s}$ intertrial interval was used to avoid intertrial phase locking.

\section{Experiment 8: high-resolution fMRI experiment without interocular suppression}

We designed two experiments using the same visual stimuli as presented to the nondominant eye of the participants from Experiments 1 and 2: a yellow octagon flashing above or below a fixation cross either synchronously (synchronous) or in one of the two asynchronous conditions ( $80 \%$ or $120 \%$; asynchronous). However, in these experiments, the visual stimuli were presented with no masking so the stimuli were fully visible. The first experiment consisted of a localization task in which the subjects had to localize the octagon as being either above or below fixation while being uninformed of the relationship between the flashing of the target and their heartbeat (see Fig. $4 a$ ). The naivety of the subjects to this relationship was important to avoid recording any brain activity resulting from interoceptive attention to their heartbeat; therefore, this relationship was not mentioned before this task.

The second experiment was a heartbeat awareness task. The stimuli were identical to the localization task, but the participants were now informed about the cardio-visual feature of the target and they had to respond if the target was flashing synchronously or not with their heartbeat (see Fig. 4b). This second task served as a functional localizer for the anterior insula regions, which have been shown previously to be activated by interoceptive attention to one's heartbeat (Critchley et al., 2004; Wiebking et al., 2014).

Participants. Eight right-handed healthy volunteers (one female) from the student population from Lausanne (age 20 -31 years, $\mu=24.5$ years) were scanned. One participant was removed from the data analysis due to motion artifacts $>2 \mathrm{~mm}$. All were right-handed by self-report; had a normal or corrected-to-normal vision; no cardiac, epilepsy, or psychiatric history; provided informed consent; and were paid for their participation $(\sim 30 \mathrm{CHF})$. The study was approved by the Research Ethics Committee of EPFL.

Methods. An MR-compatible blood volume pulse (BVP) detection sensor was placed on the middle finger of the left hand to record participants' real-time heartbeat (Critchley et al., 2004). Following the findings of Experiments 6 and 7 showing that the cardio-visual suppression effect was related to the cardiac frequency rather than phase locked to the cardiac R peak, we used a BVP sensor in the fMRI studies. The BVP measures heart rate through detection of blood perfusion to the dermis and subcutaneous tissue of the skin. Pilot testing indicated that the BVP on the fingertip was delayed by $\sim 250 \mathrm{~ms}$ compared with the ECG $\mathrm{R}$-wave, but that the frequency detected by the BVP and ECG systems was identical (also see Lu et al., 2009). An MR-compatible response box displaying two buttons was placed in the participant's right hand. The visual stimuli were generated using ExpyVR, projected on a screen placed inside the bore of the scanner behind the participant's head, and were visible through a slanted mirror. The visual stimuli were presented binocularly and the trials followed the same procedure using an eventrelated design in the localization and the heartbeat awareness tasks (see Fig. $4 a, b$ ). Trial duration was $17.5 \mathrm{~s}$; the stimuli were presented for $7.5 \mathrm{~s}$, followed by $2.5 \mathrm{~s}$ for the question display, followed by a rest epoch lasting $7.5 \mathrm{~s}$ during which a fixation cross (RGB: $233,233,233$ ) at visual angle: $\mathrm{H}: 1^{\circ}, \mathrm{V}: 1^{\circ}$ was presented in the center of the screen. During the stimuli presentation, the fixation cross became black (RGB: $0,0,0$ ) and the target (a yellow octagon; RGB: 255,255,0; visual angle: $\mathrm{H}: 3^{\circ}, \mathrm{V}: 3^{\circ}$ ) was flashed either above or below the black cross $\left(3^{\circ}\right.$ of vertical distance from the cross) synchronously or asynchronously ( $80 \%$ or $120 \%)$ to the present heartbeat of the subject as recorded by the BVP sensor. This was followed by a response epoch lasting $2.5 \mathrm{~s}$ during which the possible responses "above" or "below" were presented in the trials of the localization task and "synchronous" or "asynchronous" in the trials of the heartbeat awareness task, with an indication of which response key to press for each choice ("up" or "down"; see Fig. $4 a, b$ ). In both the fMRI localization task and the fMRI heartbeat awareness task, there were 24 trials per run and each run was repeated twice with the synchronous and asynchronous conditions presented in a random order. Each run had a duration of $420 \mathrm{~s}$.

Scanning parameters. The MRI scanner was a 7T Siemens with a 32channel Tx/Rx rf-coil (Nova Medical) (Salomon et al., 2014). The functional runs were acquired using echo-planar images of 34 axial slices (1.3 $\mathrm{mm}$ isotropic voxels with no gap) placed over the insular cortex (matrix size $160 \times 160$, FOV $210 \mathrm{~mm}$, TE $=27 \mathrm{~ms}$, TR $=2.5 \mathrm{~s}$, GRAPPA 2; see Fig. $4 d$ ). Each functional run comprised 168 volumes and lasted $420 \mathrm{~s}$ (7 $\mathrm{min})$. The anatomical run was acquired using the MP2RAGE sequence (Marques et al., 2010; $\mathrm{TE}=2.63 \mathrm{~ms}$, TR $=7.2 \mathrm{~ms}$, TI1 $=0.9 \mathrm{~s}$, TI2 $=$ $3.2 \mathrm{~s}, \mathrm{TR}=5 \mathrm{~s}$ ) and lasted $\sim 7 \mathrm{~min}$.

Data analysis. fMRI data were analyzed using the "Brain-voyager" software package (Brain Innovation) and complementary in-house software. The echo-planar images acquired during the functional runs were corrected for low frequencies (e.g., due to cardiac and breathing artifacts) and $3 \mathrm{D}$ motion and were then transformed to the native space of the anatomical run. The data of all participants were not transformed into a standardized space but rather were analyzed separately to benefit from the high spatial resolution offered by the 7T scanner. A general linear model (GLM) analysis was performed using a design matrix containing one regressor for the fixation epochs, one for the presentation of synchronous targets, one for asynchronous targets, one for the response epochs, and six additional ones taking into account the 3D motion corrections. Because respiration signals were not available, they were not regressed from the functional data. All regressors were modeled as boxcar functions convolved with a hemodynamic response function. Clusters of positive BOLD activity were used during the presentation of the stimuli (Synchronous + Asynchronous $>$ Rest contrast) in the heartbeat awareness task as localizers to select the regions of interest (ROIs) further used in the statistical analysis of the localization task. Noninsular brain regions activated by the localizer were analyzed to investigate whether the result obtained in the anterior insula was specific or if it was also found in other brain regions. The anterior cingulate cortex (ACC), right posterior superior temporal gyrus (rSTG), and occipital visual regions were consistently activated and were selected as ROIs for each subject (at $p<0.001$ FDR).

ROIs in the right and the left anterior insula were selected manually for each subject using a $p$-value threshold of $p<0.001$ (FDR corrected). Other regions consistently activated in the localizer, such as ACC, rSTG, and occipital cortex, were also selected using the same threshold. The BOLD activity in the selected ROIs during the stimuli presentation of the localization task was further analyzed by means of an event-related averaging analysis. To determine the difference between these responses, the BOLD percentage signal change responses were averaged for the synchronous and asynchronous epochs corresponding to the two data points of the peak of the BOLD response (7.5-10 s) as well as the full time course. A repeated-measures ANOVA on the mean BOLD signal with side (left/right) and cardio-visual synchrony (synchronous/asynchronous) as within-subject factors was used to explore the effects of the 
laterality of the anterior insula (right vs left) and the synchrony conditions (synchronous vs asynchronous) of the presented visual stimuli. To supplement the BOLD time course analysis, a ROI-GLM approach was used. ROI-GLM analysis was then applied to each of the ROIs (anterior insulae and other activated regions) independently using one predictor for synchronous trials and another one for asynchronous trials, as well as the motion predictors as nuisance regressors. The values of the two predictors during the localization task were then compared with a $t$ test for each ROI. To test for possible effects of cardiac activity on the results, the cardiac signal was regressed out using the RETROICOR approach (Glover et al., 2000). Using the BVP signal, the six cardiac specific regressors created by the RETROICOR toolbox were used used as control covariates in our design matrix. The data were then reanalyzed after the regression of the cardiac signals as described above.

\section{Experiment 9: High-resolution $F M R I$ experiment with CFS}

In the second fMRI experiment, we presented the same visual stimuli as in Experiment 1 and 2: masks to the dominant eye and a yellow octagon flashing above or below a fixation cross either synchronously (synchronous) or in one of the two asynchronous conditions ( $80 \%$ or $120 \%$; asynchronous) to the other eye. We used a method for dichoptic presentation of visual stimuli inside of the 7T MRI scanner (Schurger, 2009).

In the first experiment (CFS localization task), the participants were presented with the cardio-visual stimuli but were not able to see them consciously because they were suppressed by the dynamic high-contrast patterns presented simultaneously to their dominant eye. The second experiment was identical to the heartbeat awareness task of the first fMRI experiment and served the same purpose of functionally locating the anterior insula ROIs.

Participants. Nine right-handed healthy volunteers (two females; age: 22-27 years, $\mu=24.6$ years) were scanned. Participants were otherwise similar to those of Experiment 8. One participant was removed from the data analysis due to motion artifacts $>2 \mathrm{~mm}$.

Methods. The subjects were provided with a tailored pair of prism glasses to wear inside the scanner and a piece of black-covered cardboard was used to separate the visual stream of each eye from the back of their head to the screen behind them to enable a dichoptic presentation of the stimuli. Trial duration was $24 \mathrm{~s}$ : after a $6 \mathrm{~s}$ fixation epoch, the stimuli were presented for $6 \mathrm{~s}$. There were $2 \mathrm{~s}$ to respond to each of the 2 questions, which was followed by a rest epoch lasting $6 \mathrm{~s}$. During rest, a fixation cross (RGB: $0,0,0$; visual angle: $\mathrm{H}: 1^{\circ}, \mathrm{V}: 1^{\circ}$ ) was presented in the center of the field of view of both eyes (see Fig. $4 c$ ). During the stimulus presentation, dynamic high-contrast masks were displayed to the dominant eye (visual angle: $\mathrm{H}: 20^{\circ}, \mathrm{V}: 10^{\circ}$ ) and the target (yellow octagon; RGB: 255,255,0; visual angle: $\mathrm{H}: 3^{\circ}, \mathrm{V}: 3^{\circ}$ ) was flashed either above or below the fixation cross $\left(3^{\circ}\right.$ of vertical distance from the cross) to the nondominant eye synchronously or asynchronously ( $80 \%$ or $120 \%)$ to the present heartbeat of the subjects as calculated by the BVP sensor. This was followed by a first response epoch lasting $2 \mathrm{~s}$, during which the possible responses "yes" or "no" were displayed, implying the question "Did you see a yellow octagon?" The second response epoch lasted $2 \mathrm{~s}$, during which the words "above" or "below" were displayed, prompting the participants to respond to the question "Was the octagon above or below the fixation cross?" There were 32 trials in each run and each run was repeated twice with the synchronous and asynchronous conditions presented in a random order. Each run had a duration of $768 \mathrm{~s}$. The heartbeat awareness task took place exactly in the same way as in the first fMRI experiment, with the stimuli sizes adapted to the CFS setup.

Scanning parameters. The same 7T MRI-scanner as in Experiment 8 was used and the functional runs were acquired using echo-planar images of 34 axial slices ( $1.8 \mathrm{~mm}$ isotropic voxels with no gap) placed to comprise the primary visual cortex (V1), the insular cortex, and as much of the superior parietal cortex as possible (matrix size $160 \times 160$, FOV $210 \mathrm{~mm}, \mathrm{TE}=27 \mathrm{~ms}, \mathrm{TR}=2.0 \mathrm{~s}$, GRAPPA 2). Each functional run comprised 384 volumes and lasted $12.8 \mathrm{~min}$.

Data analysis. Trials in which the participants reported to have seen the yellow octagon (first question) were discarded. The same analysis as in fMRI Experiment 8 was then performed. The "Synchronous + Asynchronous $>$ Rest" contrast $(p<0.05$, FDR corrected) was used in the heartbeat awareness task to locate the anterior insula and control ROIs functionally. The laterality (left/right) and synchronicity (synchronous/ asynchronous) effects of the BOLD activation in the unconscious task were then investigated on these ROIs and the other regions activated by the localizer (ACC, rSTG, and occipital cortex) by repeated-measures ANOVA and $t$ tests. A similar ROI-GLM analysis as before was performed here. Once again, possible effects of cardiac activity on the results were tested for by regressing out the cardiac signal using the RETROICOR approach (Glover et al., 2000) as described for Experiment 8.

\section{Data analysis: all experiments}

For all experiments, accuracy and response time were measured. Accuracy was computed as the percentage of trials in which the location of the octagon was reported correctly. The main dependent measure was the duration of the target presentation (the yellow octagon) required to break suppression. Because heart rate showed considerable variability both within (SD range 1-12 BPM, mean $\sigma=3.7$ ) and between $(\sigma=12.4$ ) participants, this measure was used because it normalized the data with respect to the within- and between-subject variance for heart rate. The duration of target presentation was recorded as the total time the visual stimulus was presented on the screen when the participants indicated that they had seen the stimulus. Only correct trials were analyzed. For each participant, trials in which the reaction time exceeded 2.5 SDs from the participant's mean were defined as outliers and excluded from further analyses (total loss 5.2\% of trials). For all CFS experiments (Experiments $1,2,4,5$, and 6 ), a $t$ test was used to compare the mean accuracy and target presentation duration for synchronous and asynchronous trials. Null effects were assessed using Bayes factor (BF) tests with default prior scales (Rouder et al., 2009) using JASP (version 0.7.11). The BF allows assessment of the likelihood of the results based on the Bayesian prior. Therefore, a BF of $<0.33$ implies substantial evidence for the null hypothesis because it is 3 times more likely than the alternative hypothesis, $0.33<\mathrm{BF}<3$ suggests insensitivity of the data, and $\mathrm{BF}>3$ implies substantial evidence for the alternative hypothesis. Heartbeat data from all experiments were extracted from the ECG recording and analyzed using $t$ tests.

\section{Results}

\section{Suppression of synchronous cardio-visual stimuli: CFS}

In the first experiment, we found that interoception modulated visual awareness as synchronous cardio-visual stimuli took longer presentation durations to reach visual awareness $(\mu=3.6 \mathrm{~s}$, $\sigma=1.2)$ compared with asynchronous cardio-visual ones $(\mu=$ $3.4 \mathrm{~s}, \sigma=1.05, t_{(29)}=2, p=0.02$, Cohen's $d^{\prime}=0.38$; Fig. $\left.2 a\right)$. This result provides empirical evidence for a direct influence of the heartbeat on visual awareness (Experiment 1).

To ensure the robustness of the present heartbeat effect on visual awareness, we repeated the experiment in a new group of participants using a within-subject design (Experiment 2; Fig. $1 b$ ). Once again, synchronous cardio-visual stimulation required more time to break suppression than asynchronous stimulation $\left(t_{(14)}=3.5, p=0.008\right.$, Cohen's $d^{\prime}=0.65$; Fig. $\left.2 b\right)$.

We next tested whether our participants were able to discriminate the synchrony between the flashing stimuli and their heartbeat to assess whether explicit perception of cardio-visual synchrony could have confounded our data. To assess the participants' interoceptive awareness, we conducted Experiment 3, in which we presented the same visual stimuli (flashing either synchronously or asynchronously to each participant's heartbeat) to both eyes (without any suppression), for a duration of $6 \mathrm{~s}$. On each trial, participants were asked to indicate whether the stimulus was synchronized to their heartbeat. The results showed that participants were at chance for judging cardio-visual synchrony even when the flashing visual stimuli were fully visible $(\mu=52.8$ $\sigma=13.1, t_{(22)}=1.03$, n.s., $\mathrm{BF}=0.22$ ), suggesting substantial evidence for the null hypothesis (one-sample $t$ test vs $50 \%$ chance 
a

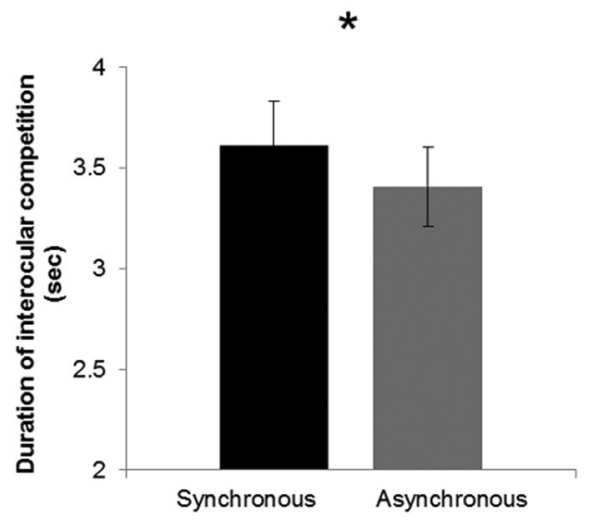

b

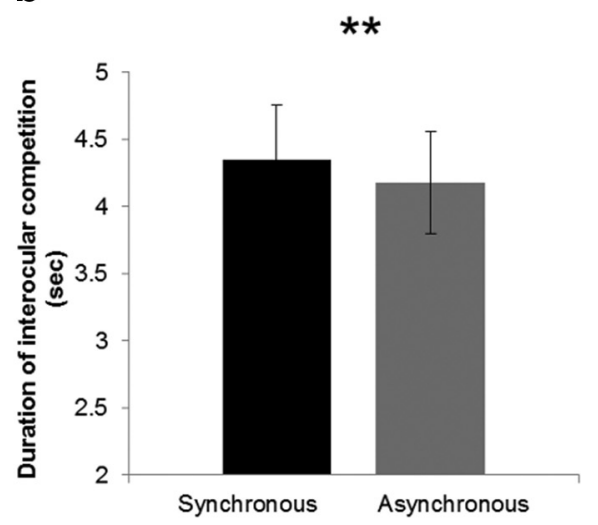

\section{Cardio-Visual Timing}

Figure 2. Suppression of synchronous cardio-visual stimuli compared with asynchronous stimuli. $\boldsymbol{a}$, Duration of target presentation required for synchronous and asynchronous cardio-visual stimuli to break suppression in Experiment $1(n=30)$. $\boldsymbol{b}$, Duration of target presentation required for synchronous and asynchronous cardio-visual stimuli to break suppression in Experiment $2(n=12)$. Note that, in both experiments, when the stimuli were synchronous to the heartbeat, they required more presentations to enter consciousness. Error bars indicate SEM $\left({ }^{*} p<0.05,{ }^{* *} p<0.01\right)$.

value). We investigated this further by correlating the interoceptive awareness accuracy scores with the cardio-visual suppression effects from the same subjects in Experiment 1. No correlation was found between these scores $(r=-0.14, p=0.52$, n.s.). A Bayesian Pearson correlation indicated a $\mathrm{BF}=0.31$, which implies substantial evidence for the null hypothesis. Therefore, these data indicate that explicit perception of cardiovisual synchrony was unlikely to underlie the present cardiovisual suppression effect. To ensure that the cardio-visual effect on visual awareness was not caused by a response or detection bias (e.g., faster responses for asynchronous stimuli after stimuli became aware), we further conducted a classical CFS control experiment (Jiang et al., 2007; Salomon et al., 2013) (Experiment 4), in which the same stimuli were presented to both eyes with the target superimposed on the patterned masks, thus not inducing any interocular suppression (Fig. 1c). Performance in Experiment 4 showed no difference between the synchronous and asynchronous cardio-visual stimulation $\left(t_{(29)}=0.27, p=0.39, \mathrm{BF}=0.34\right)$.

In addition, to ensure that the difference between synchronous and asynchronous cardio-visual stimulation was not due to subtle visual differences in the frequency of stimulation between the synchronous and asynchronous conditions, we conducted a fifth experiment (Experiment 5). Here, new subjects were shown the exact same visual stimuli that were presented to participants of Experiment 2 so that the stimuli were shown as temporally decoupled from their heartbeats (i.e., subjects in Experiment 5 saw stimuli that were recorded from other participants in Experiment 2). We reasoned that, if the difference between the synchronous and asynchronous conditions found in Experiments 1 and 2 was driven by basic visual differences (e.g., stimulation frequency) rather than by cardio-visual coupling, then such differences should also be found in Experiment 5 because the visual stimuli were identical apart from their decoupling from the cardiac signal. The results showed that, when the visual stimuli were coupled to the subjects' heartbeat, the suppression effect was significantly larger $\left(t_{(14)}=2.69, p=0.01\right)$ than when it was not coupled to the subjects heartbeat. Furthermore, when decoupled (Experiment 5), no differences between visual stimuli that were "synchronous" or "asynchronous" to the heartbeat in Experi- ment $2\left(t_{(14)}=1.2, p=0.12, \mathrm{BF}=0.5\right)$ were found and the suppression effect was not different from $0\left(t_{(14)}=1.23, p=0.23\right.$, $\mathrm{BF}=0.5)$. These BFs suggest that the results are inconclusive regarding the null or alternative hypothesis. Therefore, the same visual stimulation shown to the participants of Experiment 2, but without any cardio-visual coupling, did not induce significant differences in CFS between synchronous and asynchronous cardio-visual stimulation found for the same stimuli presented in Experiment 2 while coupled to the heartbeat. Furthermore, if the visual stimuli themselves rather than cardio-visual coupling were driving the effect, then we would expect the suppression effect (i.e., the synchronous-asynchronous difference) to be correlated between the participants of Experiment 2 and Experiment 5 because they experienced the identical visual stimulation. Subjectby-subject correlation analysis, however, did not indicate any significant correlation $(r=0.26, p=0.34)$. This indicates that cardio-visual effects on CFS (Experiments 1 and 2) depend on cardio-visual coupling and not on visual differences between synchronous and asynchronous visual stimulation.

We next sought to test whether the suppression of synchronous cardio-visual stimuli was phase-selective (i.e., locked to a specific delay after the R-wave) or if it would occur for visual stimuli that were at the same frequency of the heart but occurred at different phases of the cardiac cycle. To this end, we conducted a further CFS experiment (Experiment 6) in which the visual stimuli were either synchronous to the participants' heartbeat or delayed (by half a phase) while maintaining the same frequency. The results of Experiment 6 confirmed our predictions as there was no significant difference in the duration required to detect synchronous $(\mu=5.5 \mathrm{~s}, \sigma=1.7)$ versus delayed phase-shifted ( $\mu=5.5 \mathrm{~s}, \sigma=1.6 ; t_{(14)}=0.036$, n.s., $\mathrm{BF}=0.25$, i.e., suggesting substantial evidence for the null hypothesis) cardio-visual stimuli.

\section{Suppression of synchronous cardio-visual stimuli: visual crowding}

Next, we sought to exclude the possibility that the influence of cardiac-interoceptive signals on visual awareness was specific to the CFS task and determine whether the effect was a more general 
a

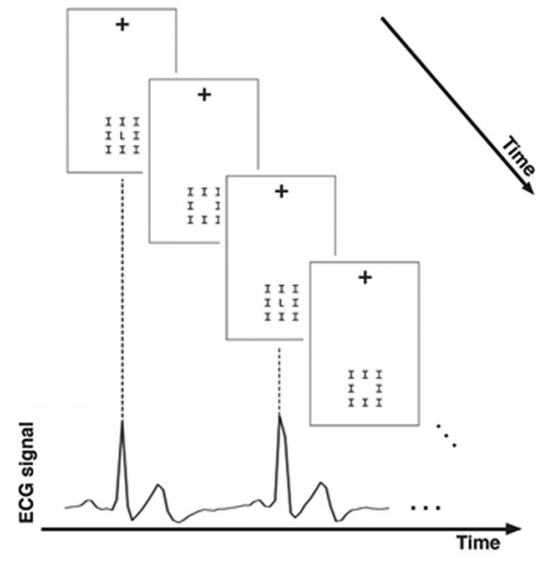

b

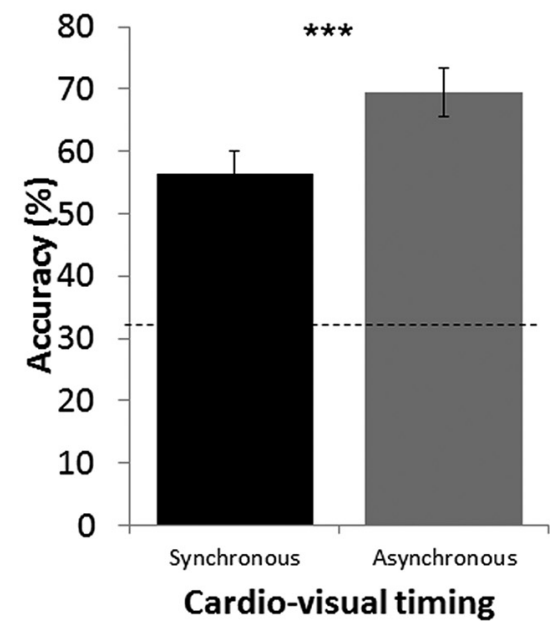

Figure 3. Crowding experiment. $\boldsymbol{a}$, Schematic of the crowding paradigm. Participants gazed on the fixation cross at the top of screen and were presented with a letter-shaped visual target that flashed either synchronously or asynchronously with respect to their heartbeat and was surrounded by an array of eight similar flankers. Participants were asked to discriminate the target as quickly and accurately as possible (three-alternative forced choice task). $\boldsymbol{b}$, Results of the crowding experiment for distance 1. Participants showed reduced accuracy for the targets flashing synchronously compared with those flashing asynchronously to the heartbeat. Error bars indicate SEM (*** $p<0.001)$.

phenomenon that also extended to other stimulation conditions. We relied on visual crowding (Experiment 7), a drastically different paradigm. Compared with CFS, which stems from interocular competition and relies on reaction time as a dependent measure, crowding is due to limits of visual discrimination in peripheral vision and is reflected by changes in accuracy measures (Whitney and Levi, 2011). While constantly fixating at the top of the screen, participants were presented with a letter-shaped visual target that was surrounded by an array of eight similar flankers at the bottom of the screen (Fig. 3a). The presence of flanking distractors causes the central target stimulus to be difficult to recognize. Although the flankers were displayed constantly, the target was flashed either synchronously or asynchronously with respect to the participants' heartbeat frequency and phase. An additional condition in which the frequency was synchronous but the visual stimulus was delayed by $300 \mathrm{~ms}$ (constant delay condition) was also included to further test the effect of frequency versus phaserelated cardio-visual signals. Participants were asked to discriminate the target (three-alternative forced choice task). As predicted (based on our CFS results), we found that cardio-visual stimulation affected the discrimination of crowded stimuli: accuracy was lower for stimuli presented synchronously with respect to the heartbeat (accuracy for the smallest center-to-center distance: $\mu=56.1$ vs $\mu=69.4, t_{(14)}=3.93, p=0.0007$, Cohen's $d^{\prime}$ $=1.1$; Fig. $3 b)$. No effect on reaction times was found. This experiment also provided additional evidence regarding the suppression of frequency-shifted, but not phase-shifted stimuli because the accuracy for the phase delay condition was significantly lower than that for the asynchronous condition $\left(t_{(14)}=\right.$ $2.3, p<0.05)$ and did not differ from the synchronous condition $\left(t_{(14)}=-0.22\right.$, n.s., $\mathrm{BF}=0.86$, i.e., inconclusive regarding the null or alternative hypothesis), replicating the findings of Experiment 6. Previous results have shown that cardiac awareness is modulated by increased cardiac activity (Khalsa et al., 2009). To assess whether the heart rate per se had any effect on the cardio-visual suppression effect, we compared effect sizes between participants with higher heart rates and lower heart rates based on a median split. Two-sample $t$ tests indicated no differences in the cardio-

visual suppression effects sizes as a function of high versus low heart rates in any of the experiments (Experiment 1, $p=$ $0.25, \mathrm{BF}=0.57$; Experiment $2, p=0.82$, $\mathrm{BF}=0.47$; Experiment 7, $p=0.87, \mathrm{BF}=$ 0.44 ; $\mathrm{BF}$ were inconclusive regarding the null or alternative hypothesis).

Our results (Experiments 1 and 2) show that visual stimuli presented synchronously with one's heartbeat take more time to break suppression and enter visual awareness compared with stimuli presented asynchronously to the heartbeat. These results indicate that the cardiac rhythm affects how an external visual stimulus gains access to awareness. This effect is not related to explicit heartbeat awareness (Experiment 3 ) or to a response or detection bias (Experiment 4) and is induced by subject-specific cardio-visual coupling and not any other information contained in the visual stimuli (Experiment 5). Importantly, we also found that this suppression extends to stimuli presented at the same frequency but phase shifted (Experiments 6 and 7) and that this effect is not dependent on interocular competition mechanisms or reaction time measures because it was also found in accuracy measures in the visual crowing experiment (Experiment 7).

These data show that cardiac interoceptive signals affect visual awareness. We argue that the present findings are compatible with predictive coding between the interoceptive and the visual system. Previous work has shown attenuation (or suppression) of sensory consequences for self-generated arm or eye movements (Guthrie et al., 1983; Blakemore et al., 1998; Shergill et al., 2013). The present data indicate that "self-generated" cardiac movements (i.e., heartbeats) are also associated with suppression of exteroceptive sensory consequences (i.e., visual signals) even if artificially produced and rarely encountered in everyday life. Our data point to the frequency of the cardiac cycle, which is identical for all afferent and efferent signals relating to cardiac information as the target for predictive suppression of these sensory consequences.

\section{Neural suppression of seen synchronous cardio-visual stimuli: fMRI}

We next wanted to investigate the neural mechanisms underlying such cardio-visual stimulation. A prime candidate region responsible for suppressing such signals is the insular cortex because of the following: (1) it is involved in the processing of interoceptive information including cardiac signals (Craig, 2002; Critchley et al., 2004), (2) it is involved in the the comparison of auditory and cardiac signals (Critchley et al., 2004), and (3) it has recently been hypothesized as a site for multimodal integration and sensory prediction related to the self (Critchley and Seth, 2012; Seth, 2013). We therefore predicted that this region would respond differently depending on the synchrony of cardio-visual stimulation. We used high-resolution fMRI at 7T (see Materials and Methods for full information concerning Experiment 8) and tested whether activity in the insular cortex reflects differences between synchronous and asynchronous cardio-visual stimulation. Regions sensitive to interoceptive attention were localized using an independent functional localizer task (Fig. $4 b$ ) adapted 
a

Fixation

Stimuli Question

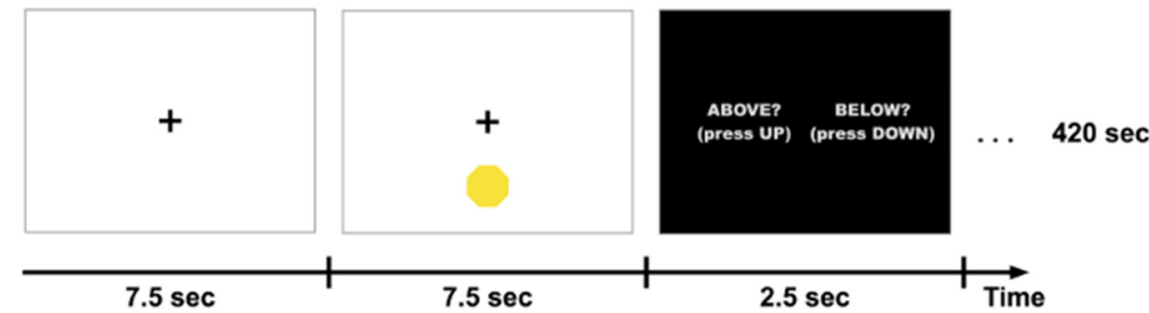

b

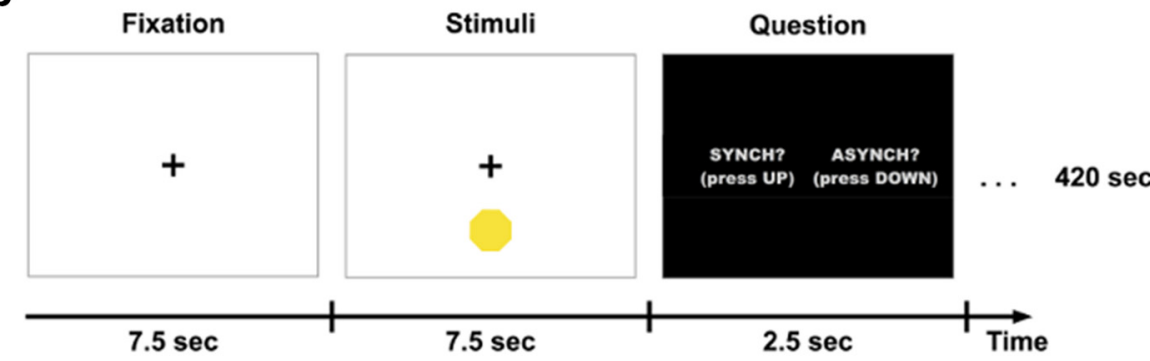

C
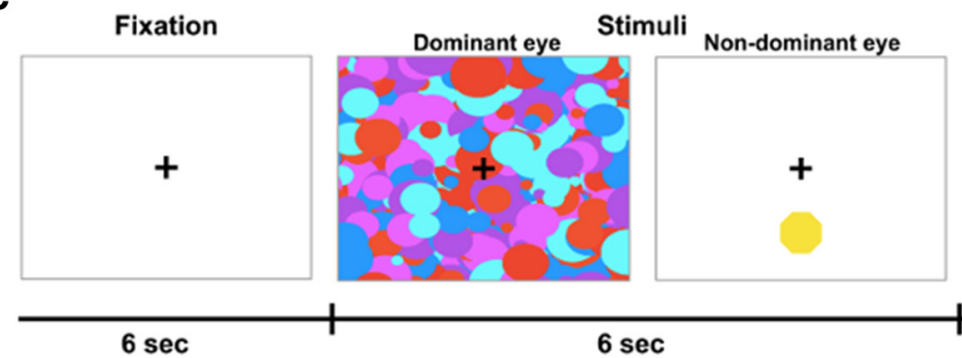

Question 1

Question 2

Figure 4. High-resolution imaging paradigms. $\boldsymbol{a}$, fMRI localization task in which participants viewed the same stimuli used in Experiments 1 and 2 but with no binocular masking. Participants were asked to report the location (above or below fixation) of the octagon which, unbeknownst to them, was flashing synchronously or asynchronously with their heartbeat. $\boldsymbol{b}$, fMRI heartbeat awareness task in which participants viewed the exact same stimuli as the localization task but were now informed that the flashing was related to their heartbeat and were requested to detect whether the flashes were synchronous or asynchronous to their current heartbeat. This was used as a functional localizer for the anterior insula regions. c, CFS localization task. In Experiment 9, the octagon (flashing synchronously or asynchronously to their heartbeat) was rendered continuously invisible by high-contrast masks presented to the dominant eye (as in Experiments 1 and 2). Participants were asked to guess the location of the stimuli and report whether they saw the target at any time during the trial. $\boldsymbol{d}$, Functional volume scanned in high-resolution fMRI at 7 T.

from an interoceptive attention task (Critchley et al., 2004) known to activate the anterior insula region. Several regions were consistently activated during the interoceptive attention task including the bilateral anterior insulae, ACC, rSTG, and occipital visual regions ( $p<0.001$, FDR corrected). In the main experiment, 8 participants viewed an unmasked octagon flashing synchronously or asynchronously to their heartbeat and were asked to report its location (i.e., above or below fixation; Fig. 4a). This task was always performed before the localizer task to ensure that participants were naive to the purpose of Experiment 8. Estimating the mean BOLD signal response in the left and right anterior insulae (as defined above) for the synchronous and asynchronous cardio-visual conditions, we found that insula activation was weaker during synchronous than asynchronous cardio-visual stimulation $\left(F_{(1,6)}=17.7, p=0.005\right)$, compatible with suppression of visually induced activation in the insula depending on cardio-visual synchrony (Fig. $5 a$ : single representative subject; Fig. 5b: group data). Analysis of other regions activated by the interoceptive task (ACC, rSTG, occipital cortex) showed no difference between the synchronous and asynchronous cardio-visual stimulation (Fig. 6). Regressing out the cardiac signal using the RETROICOR approach (Glover et al., 2000) did not affect the results. The difference between the BOLD activity in the anterior insulae between synchronous and asynchronous conditions was significant $\left(F_{(1,6)}=18.4, p=0.005\right)$, with no difference between the left and right insulae $\left(F_{(1,6)}=1.3\right.$, n.s. $)$. This suggests that the results in the anterior insulae are independent of vascular fluctuations and are more likely to reflect neuron-related BOLD changes. Furthermore, these results show that the insula is sensitive to cardio-visual synchrony, as characterized by a decreased activation during synchronous cardio-visual stimulation.

\section{Neural suppression of unseen synchronous cardio-visual} stimuli: fMRI

We next wanted to test whether this insular suppression of BOLD activity extends to cases in which the visual stimulus is rendered invisible, as was the case in our CFS experiments. To this end, we used an MRI-compatible CFS system (Schurger, 2009) and presented participants with stimuli identical to those of the first imaging experiment except that they were rendered fully invisible by CFS (see Materials and Methods for further details; Fig. 4c). CFS successfully rendered the visual stimuli invisible (as determined by subjective and objective measures). We restricted our analysis to trials in which the participants were fully unaware of the visual stimuli (78.6\% of trials). Even when the visual stimuli were rendered fully invisible through CFS, we found lower activations in the anterior insulae for synchronous compared with asynchronous stimuli $\left(F_{(1,7)}=9.3, p=0.018\right.$; see Fig. $7 a$ for a single representative subject and Fig. $7 b$ for group data). Therefore, we replicated the findings of the first fMRI experiment in an 
a

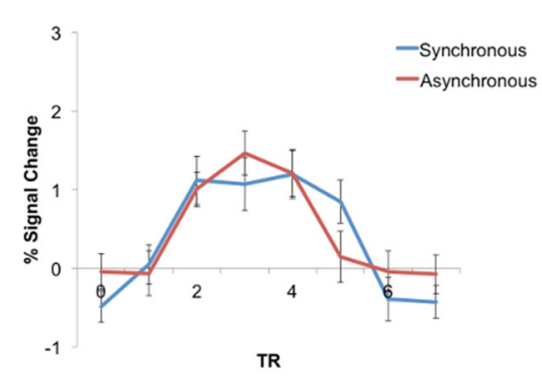

b

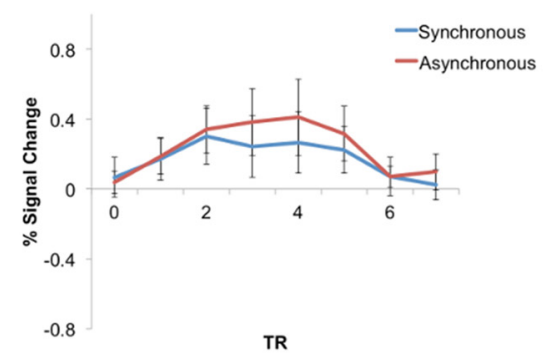

Single Subject

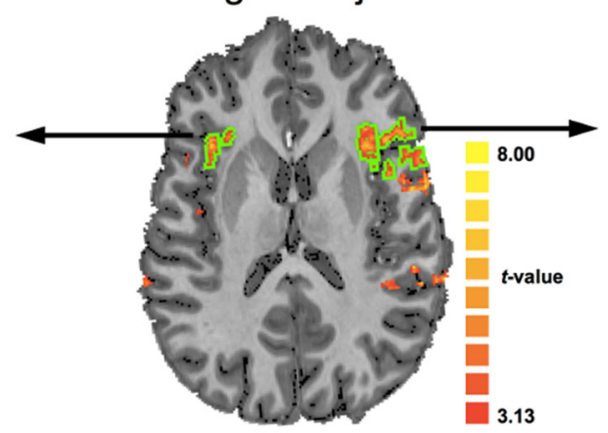

Group Average

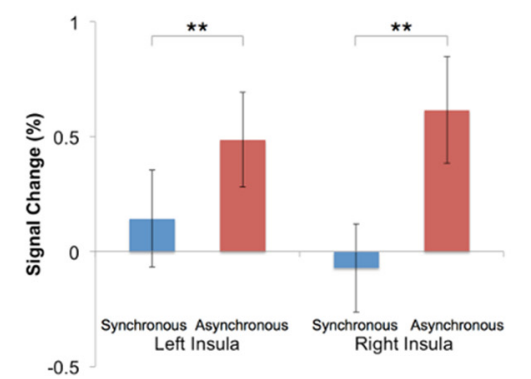

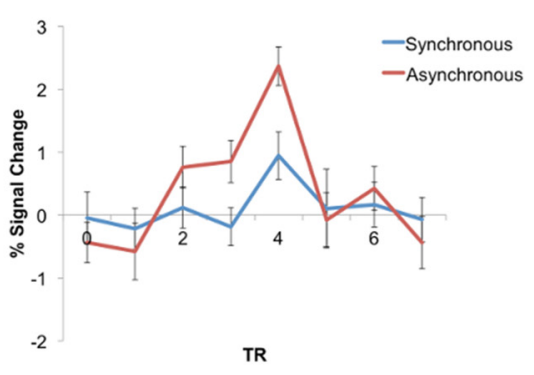

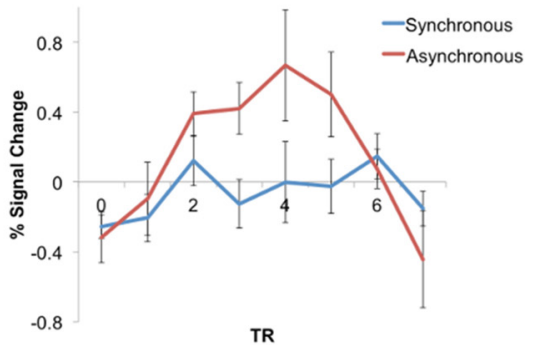

Figure 5. High-resolution imaging of cardio-visual sensitivity in the anterior insulae. $\boldsymbol{a}$, Average BOLD signal response for synchronous (blue) and asynchronous (red) cardio-visual stimuli from left and right anterior insulae of a single subject (outlined in green on axial slices). $\boldsymbol{b}$, Group average of BOLD time course for synchronous (blue) and asynchronous (red) cardio-visual stimuli from the left and right anterior insulae of all subjects. Middle, Mean of BOLD peak response for group. Error bars indicate SEM $\left(^{* *} p<0.01\right)$.

independent subject sample and extended this finding to unseen cardio-visual stimuli. Importantly, this effect was robust and stable in 14 of the 15 present fMRI participants, showing lower BOLD activity in the synchronous condition in the right anterior insula. This provides important support for the role of the anterior insula in unconscious processing of cardio-visual stimuli. To ensure further that the suppression effect was only found in the insula, we analyzed control regions as in the first fMRI experiment, which showed no differential activity between the two cardio-visual conditions. After regressing out the cardiac signal, the difference between synchronous and asynchronous conditions in the insulae was significant $\left(F_{(1,7)}=6.4, p=0.039\right)$, with no difference between the left and right insulae $\left(F_{(1,7)}=0.008\right.$, n.s. $)$.

\section{Discussion}

Collectively, the present data show that interoceptive signals of cardiac origin modulate access to visual awareness. Visual stimuli presented synchronously to the cardiac frequency required longer presentations to reach awareness (CFS: Experiments 1 and 2) and were discriminated with lower accuracy (crowding: Experiment 7). Control experiments indicated that this effect is independent of explicit heartbeat awareness (Experiment 3), not due to a response or detection bias (Experiment 4), and is induced by subject-specific cardio-visual coupling (Experiment 5). Importantly, we found that this suppression extends to stimuli presented at the same frequency but phase-shifted compared with the periodic heartbeat (Experiments 6 and 7). High-resolution imaging indicated that insular cortex showed decreased BOLD activation in response to both visible (Experiment 8 ) and invisible (Experiment 9) visual stimuli that were synchronous to the participants' heartbeat.

We suggest that this effect is due to the conflicting requirements of monitoring the heartbeat while minimizing its effects on perception. The heartbeat is a lifelong and critical signal for the organism, which must be monitored continuously and kept within tight limits to avoid, for example, arrhythmia or asystolia; such monitoring, in most instances, occurs outside of awareness because one does not experience control over one's heart. However, our heartbeat also produces widespread sensory consequences in the tactile, proprioceptive, auditory, and visual domains. For example, the heartbeat affects tactile afferent output (Macefield, 2003), muscle spindle discharge (Birznieks et al., 2012), and generates mechanical effects on the eyes modulating interocular pressure and eye movements (de Kinkelder et al., 2011). Suppression of the sensory consequences related to these cardiac effects is thus desired for an accurate perception of external stimuli. Comparable to suppression of the consequences of our actions in tactile (Blakemore et al., 1998; Bays et al., 2006; Shergill et al., 2013), auditory (McGuire et al., 1995; Baess et al., 2009; van Elk et al., 2014b), and visual domains (Volkmann et al., 1980; Guthrie et al., 1983), we propose that the present effects of the heartbeat on visual awareness reflect a basic and likely predictive mechanism to suppress the "self-generated" sensory consequences of the heartbeat from awareness. The present effect is consistent with suggested interoceptive predictive mechanisms (Seth et al., 2011; Seth, 2013; Barrett and Simmons, 2015), predicting the sensory consequences of interoceptive activity and reducing its effects on perception.

Although CFS techniques have been used extensively to investigate unconscious processing (Jiang et al., 2007; Faivre et al., 2014; Salomon et al., 2015a; Salomon et al., 2015b), the breaking CFS measure as a proxy for conscious access has been criticized recently (Stein et al., 2011; Yang et al., 2014). It has been proposed that the typical control condition in which no interocular suppression is used and no difference in suppression is found may be 


\section{Superior temporal gyrus}

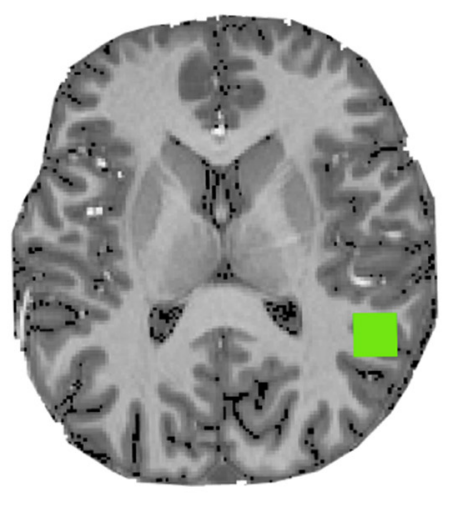

\section{Cingulate cortex}

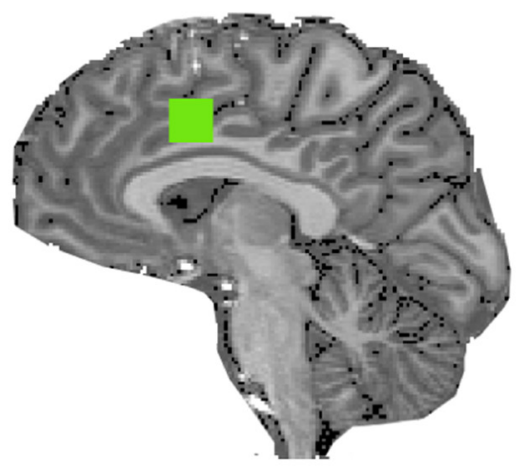

\section{Occipital cortex}

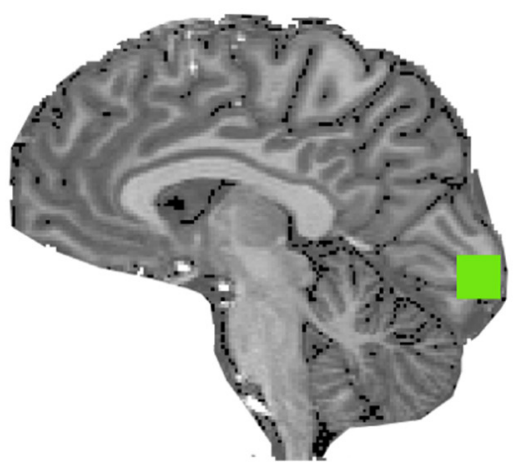

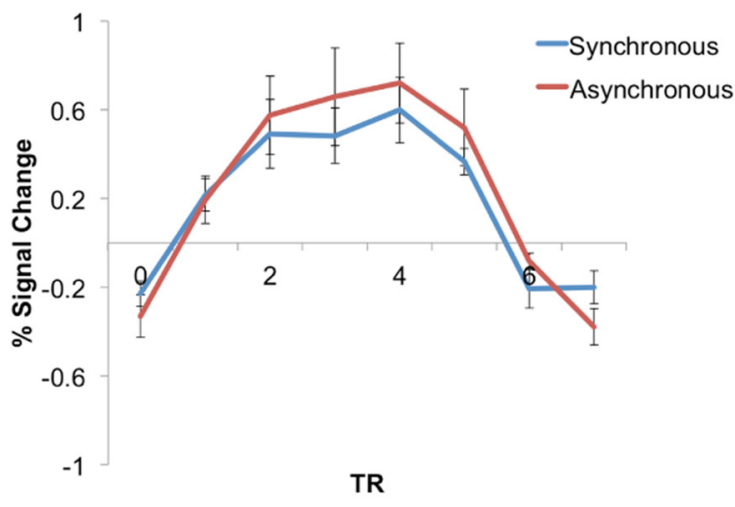
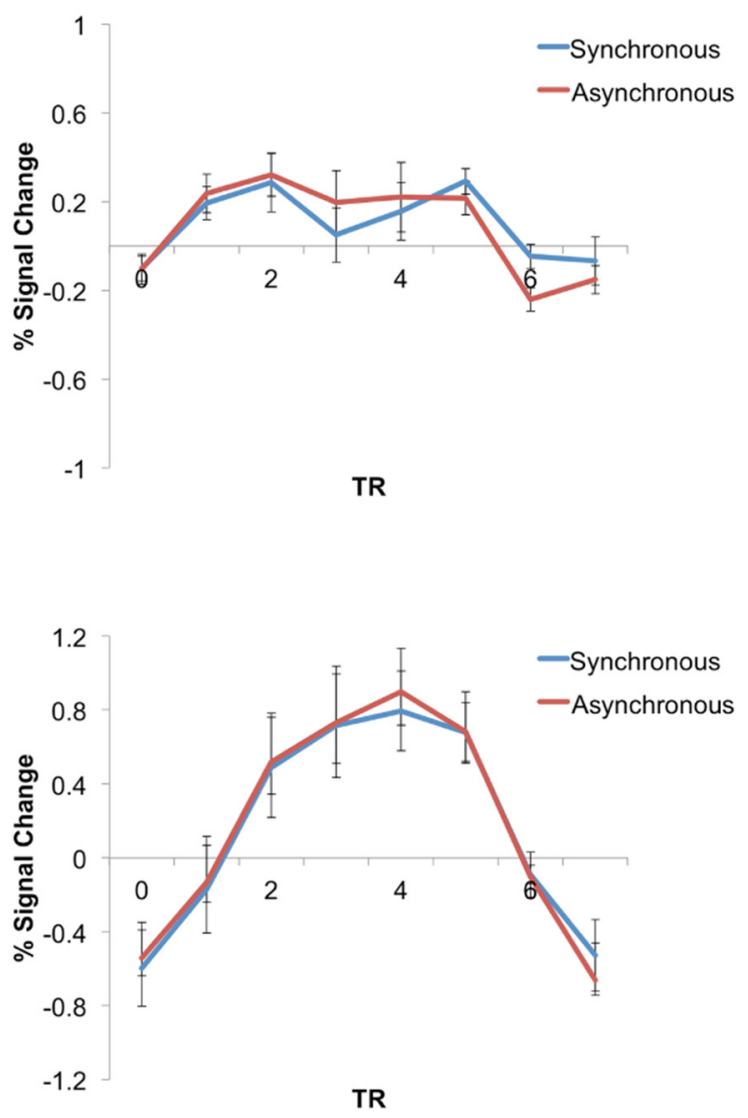

Figure 6. BOLD response in noninsular regions activated in the heart awareness task. Mean time course of the group for noninsular regions activated in the heart awareness task in fMRI Experiment 8 is shown. Note that no difference was found in BOLD response between the synchronous and asynchronous conditions in any of these regions.

insufficient to rule out that differences in reaction times are due to postperceptual processes. In the current study, however, the breaking CFS paradigms were supplemented with an additional psychophysical method of visual crowding (Experiment 7), which allowed us to replicate our finding in the accuracy domain, thus circumventing the possible limitations of time to emergence used with the CFS method. Furthermore, using Bayesian statistics to complement nonsignificant effects, we found a BF of 0.34 for the CFS control experiment (Experiment 4), which indicates that the null effect is nearly three times as likely as the alternative hypothesis. Finally, we found cortical suppression effects under full suppression, in which the participants are completely unaware of the stimuli, independently of time to emergence measures. Therefore, by using multiple paradigms, Bayesian statistics, and full-suppression methods, we are confident that our finding is independent of possible confounds related to time to emergence measures.

Interoceptive information regarding cardiac activity is conveyed by several afferent sources, including cardiac and somatosensory mechanoreceptors as well as blood vessel baroreceptors (Knapp and Brener, 1998), and is affected by several cardiac factors (Schandry et al., 1993). Previous investigations of cardiac 
a

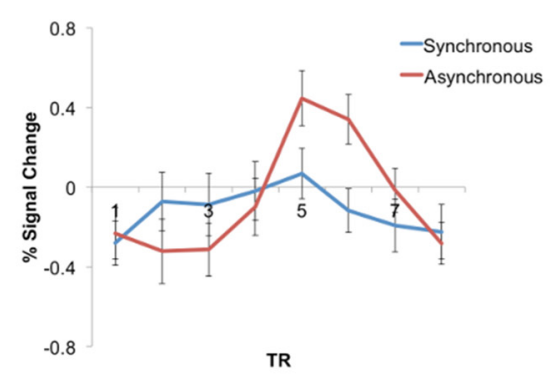

b

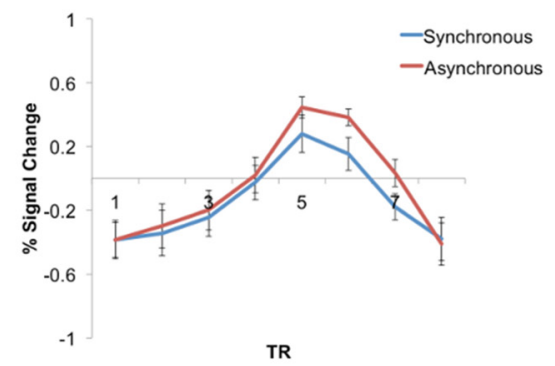

Single Subject
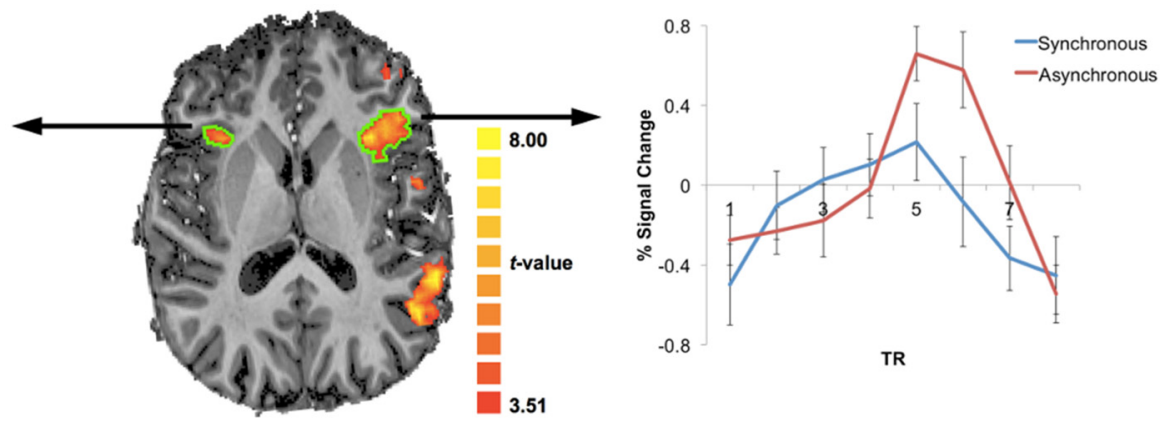

Group Average

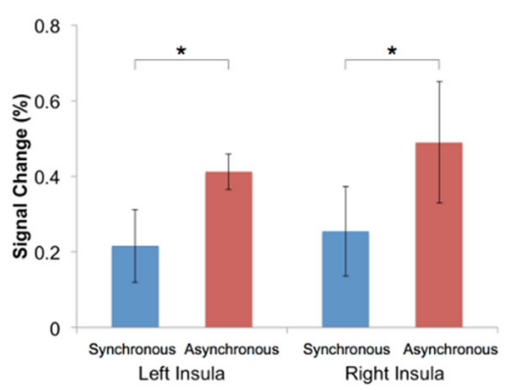

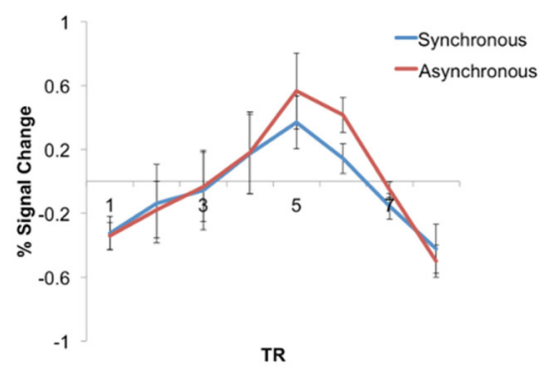

Figure 7. High-resolution imaging of cardio-visual sensitivity in the anterior insulae during CFS. a, Average BOLD signal response for synchronous (blue) and asynchronous (red) cardio-visual stimuli from left and right anterior insulae of a single subject (outlined in green on axial slices). $\boldsymbol{b}$, Group average of BOLD time course for synchronous (blue) and asynchronous (red) cardio-visual stimuli from the left and right anterior insulae of all subjects. Middle, Mean of BOLD peak response for group. Error bars indicate SEM ( $\left.{ }^{*} p<0.05\right)$.

influences on behavior and neural processing have focused on specific epochs of the cardiac cycle (e.g., systole vs diastole) and have been successful in showing cardiac effects on somatosensory (Edwards et al., 2009; Gray et al., 2009), nociceptive (Edwards et al., 2001; McIntyre et al., 2006; Edwards et al., 2008; Gray et al., 2010), and emotional (Gray et al., 2007; Gray et al., 2012; Garfinkel et al., 2014) processing. Importantly, these afferent signals have variable delays in respect to the R-wave, as shown by previous studies on heartbeat awareness (Brener et al., 1993; Ring and Brener, 1996) and heart-related neural activity (Leopold and Schandry, 2001; van Elk et al., 2014a). In contrast, the frequency of cardiac-related effects is identical across all afferent inputs. Here, we extend the aforementioned findings and show behavioral and neural suppression for visual targets synchronous to the participants' cardiac frequency. Although the heartbeat is a periodic signal, its sensory consequences differ in their temporal delay as a function of the distance from the heart. Accordingly, a predictive model (Seth et al., 2011; Brown et al., 2013) based on the frequency but regardless of the phase of the cardiac cycle could be effective for the suppression of its sensory consequences no matter where they occur compared with the heart. Consistent with this view, a previous study investigating the neural suppression of cardiac-related auditory stimuli indicated auditory suppression depending on cardiac frequency but not cardiac phase (van Elk et al., 2014a). Therefore, the present results indicate a role for cardiac frequency in the attenuation of the sensory consequences of interoceptive signals (see Aspell et al., 2013; Suzuki et al., 2013 for frequency-based effects on behavior).

At the neural level, our data show that the insular cortex is sensitive to the synchronicity of visual and cardiac signals for both visible and invisible visual stimuli. This region is thought to enable the convergence of interoceptive and exteroceptive signals (Craig, 2002; Critchley et al., 2004; Wiebking et al., 2014) and has recently also been proposed to underlie self-awareness (Damasio, 2000; Craig, 2009b; Craig, 2010; Apps and Tsakiris, 2014) and exteroceptive multisensory bodily perception and movement control in healthy and neurological patients (Karnath et al., 2005; Heydrich and Blanke, 2013). These results converge in suggesting the possible role of the insula for multimodal predictive coding (Singer et al., 2009; Seth et al., 2011; Apps and Tsakiris, 2014) and salience processing (Seeley et al., 2007). The current findings further suggest that the anterior insular cortex may constitute a site for multimodal integration of internal and external sensory signals through interoceptive predictions (Seth et al., 2011; Brown et al., 2013; Seth and Critchley, 2013; Barrett and Simmons, 2015). We propose that these predictive mechanisms allow suppressing the sensory consequences of cardiac activity by integrating internal somatic states with external sensory information (Craig, 2002; Critchley et al., 2004; Preuschoff et al., 2008).

Although the data are consistent with interoceptive predictive coding accounts in the anterior insular cortex, we cannot rule out other possible interpretations of the findings. The insular cortex has been found to be activated by a wide range of perceptual and cognitive processes (Kurth et al., 2010). The anterior insula has been implicated in temporal processing (Craig, 2009a; Wiener et al., 2010), which has been suggested to relate to its role in integrating internal interoceptive temporal cues with external signals (Wittmann, 2009; Wittmann et al., 2010). Indeed, the anterior insula has been activated in studies investigating temporal synchrony (Bushara et al., 2001) and the sense of agency and error monitoring that require matching exteroceptive sensory signals with self-generated actions (Menon et al., 2001; Klein et al., 2007; Karnath and Baier, 2010; Sperduti et al., 2011; Klein et al., 2013). Therefore, it is possible that the observed increased anterior insular activation by asynchronous cardio-visual stimuli reflects sensitivity to the temporal disparity between the visual stimulus 
and the cardiac frequency regardless of predictive mechanisms. Further experiments including manipulation of prior expectations are required to ascertain whether interoceptive predictive coding in the anterior insula underlies the reported effect.

In conclusion, the results of the present series of psychophysical experiments show that awareness for visual events is suppressed if they are synchronized to the heartbeat. Neuroimaging data indicate an important role for the insula in this suppression, which is consistent with its suggested role in multimodal predictive coding. These results demonstrate that the processing of interoceptive bodily signals in the insula has systematic effects on our conscious experience of the world.

\section{References}

Apps MA, Tsakiris M (2014) The free-energy self: a predictive coding account of self-recognition. Neurosci Biobehav Rev 41:85-97. CrossRef Medline

Aspell JE, Heydrich L, Marillier G, Lavanchy T, Herbelin B, Blanke O (2013) Turning body and self inside out visualized heartbeats alter bodily selfconsciousness and tactile perception. Psychol Sci 24:2445-2453. CrossRef Medline

Baess P, Widmann A, Roye A, Schröger E, Jacobsen T (2009) Attenuated human auditory middle latency response and evoked $40-\mathrm{Hz}$ response to self-initiated sounds. Eur J Neurosci 29:1514-1521. CrossRef Medline

Barrett LF, Simmons WK (2015) Interoceptive predictions in the brain. Nat Rev Neurosci 16:419-429. CrossRef Medline

Bays PM, Flanagan JR, Wolpert DM (2006) Attenuation of self-generated tactile sensations is predictive, not postdictive. PLoS Biol 4:e28. Medline

Birznieks I, Boonstra TW, Macefield VG (2012) Modulation of human muscle spindle discharge by arterial pulsations-functional effects and consequences. PLoS One 7:e35091. CrossRef Medline

Blakemore SJ, Wolpert DM, Frith CD (1998) Central cancellation of selfproduced tickle sensation. Nat Neurosci 1:635-640. CrossRef Medline

Bouma H (1970) Interaction effects in parafoveal letter recognition. Nature 226:177-178. CrossRef Medline

Brener J, Kluvitse C (1988) Heartbeat detection: judgments of the simultaneity of external stimuli and heartbeats. Psychophysiology 25:554-561. CrossRef Medline

Brener J, Liu X, Ring C (1993) A method of constant stimuli for examining heartbeat detection: comparison with the Brener-Kluvitse and Whitehead methods. Psychophysiology 30:657-665. CrossRef Medline

Brown H, Adams RA, Parees I, Edwards M, Friston K (2013) Active inference, sensory attenuation and illusions. Cogn Process 14:411-427. CrossRef Medline

Bushara KO, Grafman J, Hallett M (2001) Neural correlates of auditoryvisual stimulus onset asynchrony detection. J Neurosci 21:300-304. Medline

Craig AD (2009a) Emotional moments across time: a possible neural basis for time perception in the anterior insula. Philos Trans R Soc Lond B Biol Sci 364:1933-1942. CrossRef Medline

Craig AD (2009b) How do you feel-now? The anterior insula and human awareness. Nat Rev Neurosci 10:59-70. CrossRef Medline

Craig AD (2002) How do you feel? Interoception: the sense of the physiological condition of the body. Nat Rev Neurosci 3:655-666. CrossRef Medline

Craig AD (2010) The sentient self. Brain Struct Funct 214:563-577. CrossRef Medline

Critchley H, Seth A (2012) Will studies of macaque insula reveal the neural mechanisms of self-awareness? Neuron 74:423-426. CrossRef Medline

Critchley HD, Wiens S, Rotshtein P, Ohman A, Dolan RJ (2004) Neural systems supporting interoceptive awareness. Nat Neurosci 7:189-195. CrossRef Medline

Damasio AR (1999) The feeling of what happens: body and emotion in the making of consciousness. Boston: Houghton Mifflin Harcourt.

Dehaene S, Changeux JP (2011) Experimental and theoretical approaches to conscious processing. Neuron 70:200-227. CrossRef Medline

de Kinkelder R, Kalkman J, Faber DJ, Schraa O, Kok PH, Verbraak FD, van Leeuwen TG (2011) Heartbeat-induced axial motion artifacts in optical coherence tomography measurements of the retina. Invest Ophthalmol Vis Sci 52:3908-3913. CrossRef Medline

Edwards L, Ring C, McIntyre D, Carroll D (2001) Modulation of the human nociceptive flexion reflex across the cardiac cycle. Psychophysiology 38: 712-718. CrossRef Medline

Edwards L, Inui K, Ring C, Wang X, Kakigi R (2008) Pain-related evoked potentials are modulated across the cardiac cycle. Pain 137:488-494. CrossRef Medline

Edwards L, Ring C, McIntyre D, Winer JB, Martin U (2009) Sensory detection thresholds are modulated across the cardiac cycle: evidence that cutaneous sensibility is greatest for systolic stimulation. Psychophysiology 46:252-256. CrossRef Medline

Elliott R, Graf V (1972) Visual sensitivity as a function of phase of cardiac cycle. Psychophysiology 9:357-361. CrossRef Medline

Faivre N, Berthet V, Kouider S (2014) Sustained invisibility through crowding and continuous flash suppression: a comparative review. Front Psychol 5.

Garfinkel SN, Minati L, Gray MA, Seth AK, Dolan RJ, Critchley HD (2014) Fear from the heart: sensitivity to fear stimuli depends on individual heartbeats. J Neurosci 34:6573-6582. CrossRef Medline

Glover GH, Li TQ, Ress D (2000) Image-based method for retrospective correction of physiological motion effects in fMRI: RETROICOR. Magn Reson Med 44:162-167. Medline

Gray MA, Harrison NA, Wiens S, Critchley HD (2007) Modulation of emotional appraisal by false physiological feedback during fMRI. PLoS One 2:e546. CrossRef Medline

Gray MA, Rylander K, Harrison NA, Wallin BG, Critchley HD (2009) Following one's heart: cardiac rhythms gate central initiation of sympathetic reflexes. J Neurosci 29:1817-1825. CrossRef Medline

Gray MA, Minati L, Paoletti G, Critchley HD (2010) Baroreceptor activation attenuates attentional effects on pain-evoked potentials. Pain 151: 853-861. CrossRef Medline

Gray MA, Beacher FD, Minati L, Nagai Y, Kemp AH, Harrison NA, Critchley HD (2012) Emotional appraisal is influenced by cardiac afferent information. Emotion 12:180-191. CrossRef Medline

Guthrie BL, Porter JD, Sparks DL (1983) Corollary discharge provides accurate eye position information to the oculomotor system. Science 221: 1193-1195. CrossRef Medline

Heydrich L, Blanke O (2013) Distinct illusory own-body perceptions caused by damage to posterior insula and extrastriate cortex. Brain 136: 790-803. CrossRef Medline

Jiang Y, Costello P, He S (2007) Processing of invisible stimuli: advantage of upright faces and recognizable words in overcoming interocular suppression. Psychol Sci 18:349-355. CrossRef Medline

Karnath HO, Baier B (2010) Right insula for our sense of limb ownership and self-awareness of actions. Brain Struct Funct 214:411-417. CrossRef Medline

Karnath HO, Baier B, Nägele T (2005) Awareness of the functioning of one's own limbs mediated by the insular cortex? J Neurosci 25:7134-7138. CrossRef Medline

Khalsa SS, Rudrauf D, Sandesara C, Olshansky B, Tranel D (2009) Bolus isoproterenol infusions provide a reliable method for assessing interoceptive awareness. Int J Psychophysiol 72:34-45. CrossRef Medline

Klein TA, Endrass T, Kathmann N, Neumann J, von Cramon DY, Ullsperger M (2007) Neural correlates of error awareness. Neuroimage 34:17741781. CrossRef Medline

Klein TA, Ullsperger M, Danielmeier C (2013) Error awareness and the insula: links to neurological and psychiatric diseases. Front Hum Neurosci 7.

Knapp K, Brener J (1998) Mechanoreceptors responsible for transducing heartbeat sensations. Psychophysiology 35:S51.

Knapp-Kline K, Kline JP (2005) Heart rate, heart rate variability, and heartbeat detection with the method of constant stimuli: slow and steady wins the race. Biol Psychol 69:387-396. CrossRef Medline

Koriath JJ, Lindholm E (1986) Cardiac-related cortical inhibition during a fixed foreperiod reaction time task. Int J Psychophysiol 4:183-195. CrossRef Medline

Kurth F, Zilles K, Fox PT, Laird AR, Eickhoff SB (2010) A link between the systems: functional differentiation and integration within the human insula revealed by meta-analysis. Brain Struct Funct 214:519-534. CrossRef Medline

Lacey JI, Lacey BC (1970) Some autonomic-central nervous system interrelationships. In: Physiological correlates of emotion (Black P, ed), pp 205227. Philadelphia: Elsevier Ltd.

Leopold C, Schandry R (2001) The heartbeat-evoked brain potential in pa- 
tients suffering from diabetic neuropathy and in healthy control persons. Clin Neurophysiol 112:674-682. CrossRef Medline

Levi DM (2008) Crowding-an essential bottleneck for object recognition: a mini-review. Vision Res 48:635-654. CrossRef Medline

Lu G, Yang F, Taylor JA, Stein JF (2009) A comparison of photoplethysmography and ECG recording to analyse heart rate variability in healthy subjects. J Med Eng Technol 33:634-641. CrossRef Medline

Macefield VG (2003) Cardiovascular and respiratory modulation of tactile afferents in the human finger pad. Exp Physiol 88:617-625. CrossRef Medline

Marques JP, Kober T, Krueger G, van der Zwaag W, Van de Moortele PF, Gruetter R (2010) MP2RAGE, a self bias-field corrected sequence for improved segmentation and T1-mapping at high field. Neuroimage 49: 1271-1281. CrossRef Medline

McGuire PK, Silbersweig DA, Wright I, Murray RM, David AS, Frackowiak RS, Frith CD (1995) Abnormal monitoring of inner speech: a physiological basis for auditory hallucinations. Lancet 346:596-600. CrossRef Medline

McIntyre D, Edwards L, Ring C, Parvin B, Carroll D (2006) Systolic inhibition of nociceptive responding is moderated by arousal. Psychophysiology 43:314-319. CrossRef Medline

Menon V, Adleman NE, White CD, Glover GH, Reiss AL (2001) Errorrelated brain activation during a $\mathrm{Go} / \mathrm{NoGo}$ response inhibition task. Hum Brain Mapp 12:131-143. CrossRef Medline

Park HD, Correia S, Ducorps A, Tallon-Baudry C (2014) Spontaneous fluctuations in neural responses to heartbeats predict visual detection. Nat Neurosci 17:612-618. CrossRef Medline

Preuschoff K, Quartz SR, Bossaerts P (2008) Human insula activation reflects risk prediction errors as well as risk. J Neurosci 28:2745-2752. CrossRef Medline

Ring C, Brener J (1996) Influence of beliefs about heart rate and actual heart rate on heartbeat counting. Psychophysiology 33:541-546. CrossRef Medline

Rouder JN, Speckman PL, Sun D, Morey RD, Iverson G (2009) Bayesian $t$ tests for accepting and rejecting the null hypothesis. Psychon Bull Rev 16:225-237. CrossRef Medline

Salomon R, Darulova J, Narsude M, van der Zwaag W (2014) Comparison of an 8-channel and a 32-channel coil for high-resolution fMRI at $7 \mathrm{~T}$. Brain Topogr 27:209-212. CrossRef Medline

Salomon R, Lim M, Herbelin B, Hesselmann G, Blanke O (2013) Posing for awareness: proprioception modulates access to visual consciousness in a continuous flash suppression task. J Vis 13:2. CrossRef Medline

Salomon R, Kaliuzhna M, Herbelin B, Blanke O (2015a) Balancing awareness: Vestibular signals modulate visual consciousness in the absence of awareness. Conscious Cogn 36:289-297. CrossRef Medline

Salomon R, Galli G, Łukowska M, Faivre N, Ruiz JB, Blanke O (2015b) An invisible touch: Body-related multisensory conflicts modulate visual consciousness. Neuropsychologia pii: S0028-3932(15)30210-4. CrossRef Medline

Sandman CA, McCanne TR, Kaiser DN, Diamond B (1977) Heart rate and cardiac phase influences on visual perception. J Comp Physiol Psychol 91:189-202. CrossRef Medline

Schandry R, Bestler M, Montoya P (1993) On the relation between cardiodynamics and heartbeat perception. Psychophysiology 30:467-474. CrossRef Medline

Schurger A (2009) A very inexpensive MRI-compatible method for dichoptic visual stimulation. J Neurosci Methods 177:199-202. CrossRef Medline

Seeley WW, Menon V, Schatzberg AF, Keller J, Glover GH, Kenna H, Reiss
AL, Greicius MD (2007) Dissociable intrinsic connectivity networks for salience processing and executive control. J Neurosci 27:2349-2356. CrossRef Medline

Seth AK (2013) Interoceptive inference, emotion, and the embodied self. Trends Cogn Sci 17:565-573. CrossRef Medline

Seth AK, Critchley HD (2013) Extending predictive processing to the body: emotion as interoceptive inference. Behav Brain Sci 36:227-228. CrossRef Medline

Seth AK, Suzuki K, Critchley HD (2011) An interoceptive predictive coding model of conscious presence. Front Psychol 2.

Shergill SS, White TP, Joyce DW, Bays PM, Wolpert DM, Frith CD (2013) Modulation of somatosensory processing by action. Neuroimage 70:356362. CrossRef Medline

Singer T, Critchley HD, Preuschoff K (2009) A common role of insula in feelings, empathy and uncertainty. Trends Cogn Sci 13:334-340. CrossRef Medline

Sperduti M, Delaveau P, Fossati P, Nadel J (2011) Different brain structures related to self-and external-agency attribution: a brief review and metaanalysis. Brain Struct Funct 216:151-157. CrossRef Medline

Stein T, Hebart MN, Sterzer P (2011) Breaking continuous flash suppression: a new measure of unconscious processing during interocular suppression? Front Hum Neurosci 5.

Suzuki K, Garfinkel SN, Critchley HD, Seth AK (2013) Multisensory integration across exteroceptive and interoceptive domains modulates selfexperience in the rubber-hand illusion. Neuropsychologia 51:2909-2917. CrossRef Medline

Tsuchiya N, Koch C (2005) Continuous flash suppression reduces negative afterimages. Nat Neurosci 8:1096-1101. CrossRef Medline

van Elk M, Lenggenhager B, Heydrich L, Blanke O (2014a) Suppression of the auditory N1-component for heartbeat-related sounds reflects interoceptive predictive coding. Biol Psychol 99:172-182. CrossRef Medline

van Elk M, Salomon R, Kannape O, Blanke O (2014b) Suppression of the N1 auditory evoked potential for sounds generated by the upper and lower limbs. Biol Psychol 102:108-117. CrossRef Medline

Volkmann FC, Riggs LA, Moore RK (1980) Eyeblinks and visual suppression. Science 207:900-902. CrossRef Medline

Walker BB, Sandman CA (1982) Visual evoked potentials change as heart rate and carotid pressure change. Psychophysiology 19:520-527. CrossRef Medline

Whitney D, Levi DM (2011) Visual crowding: a fundamental limit on conscious perception and object recognition. Trends Cogn Sci 15:160-168. CrossRef Medline

Wiebking C, Duncan NW, Tiret B, Hayes DJ, Marjaǹska M, Doyon J, Bajbouj M, Northoff G (2014) GABA in the insula-a predictor of the neural response to interoceptive awareness. Neuroimage 86:10-18. CrossRef Medline

Wiener M, Turkeltaub P, Coslett HB (2010) The image of time: a voxel-wise meta-analysis. Neuroimage 49:1728-1740. CrossRef Medline

Wittmann M (2009) The inner experience of time. Philos Trans R Soc Lond B Biol Sci 364:1955-1967. CrossRef Medline

Wittmann M, Simmons AN, Aron JL, Paulus MP (2010) Accumulation of neural activity in the posterior insula encodes the passage of time. Neuropsychologia 48:3110-3120. CrossRef Medline

Yang E, Brascamp J, Kang M-S, Blake R (2014) On the use of continuous flash suppression for the study of visual processing outside of awareness. Front Psychol 5. 